\title{
Massa seca e teores de nutrientes de plantas de milho sob efeito de águas salinas e biochar
}

\section{Dry mass and nutrient content of maize plants under effect of saline waters and biochar}

\author{
Maria Eugênia da Costa ${ }^{1}$, Neyton de Oliveira Miranda ${ }^{2}$, Alexandre Santos Pimenta ${ }^{3}$, Erlen Kaline Ávila Nascimento ${ }^{4}$, Ana Paula \\ Medeiros dos Santos Rodrigues ${ }^{5}$, Antonio Francisco de Mendonça Júnior ${ }^{6}$
}

Resumo: O milho é cultivado em todo o Brasil para uso na alimentação humana e animal e como matéria prima de biocombustíveis e indústria. Sua produtividade é prejudicada pela degradação de água e solo, da qual a salinização é grave na região semiárida. Três experimentos foram realizados em solos (Argissolo, Cambissolo e Neossolo flúvico) do estado do Rio Grande do Norte para avaliar o efeito do biochar sobre a massa seca e nutrientes de plantas de milho irrigado com águas salinas. Os solos preenchiam colunas de PVC dispostas em casa de vegetação da Universidade Federal Rural do Semiárido, em Mossoró. O delineamento era inteiramente casualisado em esquema fatorial com quatro repetições. Os fatores estudados foram doses de biochar $(0 ; 0,5 ; 1,0 ;$ e $1,5 \%)$ e níveis de salinidade da água de irrigação $\left(0,57 ; 2,65\right.$ e 4,5 dS m$\left.{ }^{-1}\right)$. O biochar foi obtido da carbonização de Prosopis juliflora (Sw.). Aos 40 dias após emergência determinou-se a massa seca da parte aérea e o teor de N, P, $\mathrm{K}, \mathrm{Ca}$ e Mg das plantas. Os dados foram submetidos à análise de variância e análise de regressão. As respostas da massa seca $\mathrm{e}$ teores de nutrientes do milho indicam que o biochar pode mitigar a salinidade da água de irrigação, dependendo da dose aplicada e do tipo de solo.

Palavras-chave: Zea mays L.; Salinidade; Manejo do solo; Carvão vegetal.

Abstract: Maize is grown throughout Brazil and used for feeding humans and animals and as a raw material for biofuels and industry. Its yield is impaired by of soil and water degradation, such as salinization, which is more serious in semi-arid regions. Three experiments were carried out in different soils (Acrisol, Cambisol, and Fluvisol) of the state of Rio Grande do Norte with the objective of evaluating biochar effect on dry mass and nutrient content of maize plants irrigated with saline water. The treatments were applied in PVC columns in a greenhouse at the Federal Rural Semiarid University, in Mossoró, according to a completely randomized design in a factorial scheme with four replications. The factors studied were biochar doses $(0,0.5,1.0$, and $1.5 \%)$ and irrigation water salinity levels $\left(0.57,2.65\right.$, and $\left.4.5 \mathrm{dS} \mathrm{m}^{-1}\right)$. Biochar was obtained from the carbonization of Prosopis juliflora (Sw.). At 40 days after emergence, the shoot dry mass and the plant contents of $\mathrm{N}, \mathrm{P}, \mathrm{K}, \mathrm{Ca}$ and $\mathrm{Mg}$ were determined. Data were submitted to analysis of variance and regression analysis. Responses of shoot dry mass and maize nutrient contents indicate that biochar can mitigate irrigation water salinity, depending on the dose applied and the soil type.

Key words: Zea mays L; Soil salinity; Soil management; Charcoal.

\footnotetext{
*Autor para correspondência

Recebido para publicação em 04/09/2018; aprovado em 21/11/2018

${ }^{1}$ Professora do Departamento de Ciências Agronômicas e Florestais da Universidade Federal Rural do Semi-Árido; eugenia.ufersa@gmail.com.

${ }^{2}$ Professor do Departamento de Ciências Agronômicas e Florestais da Universidade Federal Rural do Semi-Árido; neyton@ufersa.edu.br

${ }^{3}$ Professor da Unidade Acadêmica Especializada em Ciências Agrárias da Universidade Federal do Rio Grande do Norte; aspimenta@ufrnet.br.

${ }^{4}$ Departamento de Ciências Agronômicas e Florestais da Universidade Federal Rural do Semi-Árido; erlenkaline@ gmail.com

${ }^{5}$ Universidade Estadual do Rio Grande do Norte; anapaulamsr@yahoo.com.br

${ }^{6}$ Professor da Universidade Federal Rural de Pernambuco; agromendoncajr@yahoo.com.br
} 


\section{INTRODUÇÃO}

O milho (Zea mays L.) é importante economicamente em todo o Brasil por ser usado na alimentação humana e animal e como matéria prima para biocombustíveis e indústrias de alta tecnologia (FORNASIERI FILHO, 2007). A produção brasileira foi de $63.643 .423 \mathrm{t}$, com média de $4.868 \mathrm{~kg} \mathrm{ha}^{-1} \mathrm{e}$ $3908 \mathrm{~kg} \mathrm{ha}^{-1}$ nas duas safras em 2016 (IBGE, 2017). As maiores produtividades foram obtidas no Paraná $\left(8025 \mathrm{~kg} \mathrm{ha}^{-1}\right.$ e $4897 \mathrm{~kg}$ $\mathrm{ha}^{-1}$ ). A média da região Nordeste foi de $1500 \mathrm{~kg} \mathrm{ha}^{-1}$, e no Rio Grande do Norte foi de $382 \mathrm{~kg} \mathrm{ha}^{-1}$.

A baixa produtividade é atribuída a práticas agrícolas que causam a degradação do solo e água, diminuição do carbono do solo, erosão, depleção de nutrientes, compactação e salinização (FAO, 2011). A salinidade é um dos estresses mais limitantes à produtividade agrícola (FEIJÃO et al., 2013) e é mais grave e de difícil solução em regiões semiáridas devido ao clima, geologia, qualidade da água e manejo da irrigação (ARAÚJO et al., 2010; SOUZA et al., 2016).

O clima semiárido do Nordeste do Brasil favorece a salinização do solo, mesmo se aplicada água de boa qualidade, pois a temperatura e a evaporação são altas e a precipitação é baixa, além do manejo inadequado da irrigação. Entre as escassas fontes de água, algumas possuem altos teores de sais, devido ao material de origem do solo. Nestas condições, as alternativas são: usar água de poços situados no cristalino, com maior teor de sais do que os aquíferos sedimentares; reutilizar águas de drenagem com alto teor de sais solúveis, prejudicando algumas culturas e o solo; ou misturar águas com diferentes teores de sais (LACERDA et al., 2011; SILVA et al., 2016; SOUZA et al., 2016).

A salinidade prejudica as plantas por efeitos osmóticos, tóxicos e nutricionais. O efeito osmótico reduz a absorção de água pelas plantas. Alguns íons específicos ou alguns íons em excesso se tornam tóxicos por entrar no fluxo de transpiração, causar danos às folhas, alterar a estrutura e funcionamento da membrana plasmática e inibir a atividade de enzimas vitais ao metabolismo, reduzindo o crescimento ou prejudicando a absorção de elementos essenciais (FEIJÃO et al., 2013; SILVA et al., 2016; SOUSA et al.. 2012). Além disso, o excesso de sais solúveis e/ou sódio trocável prejudica a estrutura do solo e, por isto, o desenvolvimento das raízes das plantas, pois limita a infiltração de água no solo e dificulta a absorção de água do solo pelas plantas (HOLANDA et al., 2010).

A adoção de espécies tolerantes à salinidade e sistemas de irrigação eficientes e bem manejados permite cultivar solos salinos e usar água de qualidade inferior (LACERDA et al., 2011). O milho é moderadamente sensível à salinidade do solo. Sua produtividade se reduz em $12 \%$ a cada aumento unitário da salinidade acima de $1,7 \mathrm{dS} \mathrm{m} \mathrm{m}^{-1}$ e massa seca é prejudicada a partir de 1,6 dS m${ }^{-1}$ (AYERS; WESTCOT, 1999).

A recuperação de solos salinizados pode ser feita com aplicação de lâmina de água que lixivie o excesso de sais, além de gesso ou matéria orgânica (MIRANDA et al., 2011). A adição de matéria orgânica melhora a agregação do solo, diminui a dispersão promovida pelo sódio, com benefício à condutividade hidráulica, taxa de infiltração e retenção de água e nutrientes no solo (BENITES et al., 2009; MIRANDA et al., 2011). A decomposição da matéria orgânica reduz a percentagem de sódio trocável, porque libera $\mathrm{CO}_{2}$ e ácidos orgânicos, além de cálcio e magnésio, que deslocam o sódio (MIRANDA et al., 2011; SOUSA et al., 2012).

A aplicação do biochar oriundo da carbonização de biomassa sob suprimento limitado de oxigênio é uma alternativa à matéria orgânica e persiste no solo por muito mais tempo (BENITES et al., 2009). Ele é poroso, rico em carbono e contém grande quantidade de estruturas orgânicas e elementos inorgânicos, entre os quais macro e micronutrientes necessários às plantas. Sua grande superfície específica e abundância de microporos permitem absorver e imobilizar poluentes orgânicos e inorgânicos em solos e águas. Além de melhorar a fertilidade do solo, a aplicação de biochar aumenta a retenção de nutrientes e de água (NOVAK et al., 2016). Por isso, seu uso como condicionador do solo aumenta a produtividade de culturas submetidas a estresses em solos degradados (EKEBAFE et al., 2013; THOMAS et al., 2013).

Em analogia à alta capacidade do carvão ativado em absorver sais, sendo utilizado em processos industriais de dessalinização, o biochar tem efeito de sorção de sais, mitigando seus efeitos osmóticos e de toxicidade iônica, além de aumentar a disponibilidade de água no solo para as plantas (EKEBAFE et al., 2013; THOMAS et al., 2013). Ele se liga a poluentes e diminui seus efeitos sobre as plantas, bem como reduz a lixiviação de nitrato e agroquímicos para corpos de água (EKEBAFE et al., 2013; NOVAK et al., 2016).

Este trabalho visou avaliar o efeito de doses de biochar sobre massa seca e teores de nutrientes em plantas de milho irrigado com água salina em solos da região oeste do estado do Rio Grande do Norte, Brasil.

\section{MATERIAL E MÉTODOS}

O trabalho foi desenvolvido entre janeiro e outubro de 2015, em casa de vegetação do campus oeste da Universidade Federal Rural do Semiárido, UFERSA, localizada em MossoróRN. As coordenadas geográficas são $5^{\circ} 11^{\prime} \mathrm{S}$ e $37^{\circ} 20^{\prime} \mathrm{O}$ e a altitude de $18 \mathrm{~m}$. O clima local é semiárido e, de acordo com a classificação de Koeppen, é do tipo BSwh', seco e muito quente, com duas estações climáticas: uma seca, que vai geralmente de junho a janeiro, e uma chuvosa, de fevereiro a maio.

Os tratamentos foram aplicados em colunas de PVC de $200 \mathrm{~mm}$ de diâmetro e $400 \mathrm{~mm}$ de altura $\left(12566,4 \mathrm{~cm}^{3}\right)$. Nelas, o biochar foi misturado a três solos da região oeste do estado Rio Grande do Norte, coletadas na profundidade de $0-20 \mathrm{~cm}$ e classificados segundo Santos et al. (2013), como Argissolo (AS), coletado no distrito de Alagoinha, em Mossoró; Cambissolo (CS) coletado em Upanema -RN e Neossolo flúvico (NF), coletado às margens do Rio Angicos, em Mossoró. Na Tabela 1 é apresentada a caracterização química e física dos solos utilizados no experimento, conforme metodologias da EMBRAPA (2011). 
Tabela 1. Caracterização física e química dos solos Argissolo (AS), Cambissolo (CS) e Neossolo Flúvico (NF) antes da aplicação de biochar e águas salinas

\begin{tabular}{|c|c|c|c|c|c|c|c|c|c|c|c|c|c|}
\hline SOLO & $\mathrm{pH}$ & MOS & $\mathrm{P}$ & $\mathrm{K}$ & $\mathrm{Na}$ & $\mathrm{Ca}$ & $\mathrm{Mg}$ & $\mathrm{Al}$ & $(\mathrm{H}+\mathrm{Al})^{1}$ & CTC & Areia & Silte & Argila \\
\hline & & $\mathrm{g} \mathrm{kg}^{-1}$ & \multicolumn{4}{|c|}{-----mg dm ${ }^{-3}----$} & \multicolumn{4}{|c|}{$\mathrm{cmol}_{\mathrm{c}} \mathrm{dm}^{-3}-\mathrm{c}^{-}$} & \multicolumn{3}{|c|}{$---\mathrm{kg} \mathrm{kg}^{-1}-\cdots$} \\
\hline AS & 5,7 & 20,6 & 9,0 & 45 & 8,6 & 1,36 & 0,84 & 1,2 & 2,0 & 4,35 & 0,91 & 0,03 & 0,06 \\
\hline CS & 6,7 & 16,7 & 0,3 & 299 & 39,0 & 7,46 & 1,84 & 0,0 & 1,3 & 11,53 & 0,56 & 0,08 & 0,36 \\
\hline $\mathrm{NF}$ & 8,2 & 21,7 & 47,1 & 139 & 23,6 & 12,6 & 1,12 & 0,0 & 0,0 & 14,18 & 0,60 & 0,26 & 0,14 \\
\hline
\end{tabular}

MOS é Matéria Orgânica do solo; (H+Al) é Acidez potencial; CTC é capacidade de troca de cátions.

Cada solo constituiu um experimento realizado em delineamento inteiramente casualisado com quatro repetições em esquema fatorial, que constou de três níveis de salinidade da água $\left(0,57 ; 2,65\right.$ e $\left.4,5 \mathrm{dS} \mathrm{m}^{-1}\right)$ e quatro doses de biochar em volume $(0 ; 0,5 \%$ - $19 \mathrm{~g}$ por coluna; $1,0 \%$ - $38 \mathrm{~g}$ por coluna e $1,5 \%$ - 57 g por coluna), considerando a densidade do biochar de $0,3 \mathrm{~kg} \mathrm{~cm}^{-3}$.

As águas utilizadas possuíam três níveis de salinidade: água de abastecimento público $\left(0,57 \mathrm{dS} \mathrm{m}^{-1}\right)$; água produzida para representar um poço raso localizado na UFERSA $(4,5 \mathrm{dS}$ $\left.\mathrm{m}^{-1}\right)$; água resultante da mistura das duas anteriores $(2,65 \mathrm{dS} \mathrm{m}$ $\left.{ }^{1}\right)$. A água produzida constou da mistura dos sais $\mathrm{NaCl}$,
CaCl.2H2O e MgSO4.6H2O para obter a relação catiônica em mol $_{c}: \mathrm{Na}: \mathrm{Ca}: \mathrm{Mg}$ de 7:2:1. As características químicas das águas, determinadas conforme metodologia de Richards (1954) estão apresentadas na tabela 2.

O biochar obtido da carbonização de Algaroba (Prosopis juliflora (Sw.) DC.) foi triturado e passado em peneira de $4 \mathrm{~mm}$, e apresentou granulometria entre 1,0 e $2,0 \mathrm{~mm}$. Em sua composição, o carvão vegetal possuía 5,43 \% de umidade, $63 \%$ de carbono fixo, $16 \%$ de cinzas e $21 \%$ de materiais voláteis. Os principais macronutrientes possuíam os seguintes teores em $\mathrm{g}$ $\mathrm{kg}^{-1}: \mathrm{N}-7,9 ; \mathrm{P}-1,4 ; \mathrm{K}-2,0 ; \mathrm{Ca}-9,95$ e $\mathrm{Mg}-0,55$.

Tabela 2. Características químicas das águas utilizadas na irrigação do milho recebendo doses de biochar em três tipos de solos

\begin{tabular}{|c|c|c|c|c|c|c|c|c|c|c|c|c|}
\hline Água & $\mathrm{pH}$ & $\mathrm{CE}$ & $\mathrm{K}^{+}$ & $\mathrm{Na}^{+}$ & $\mathrm{Mg}^{+}$ & $\mathrm{Cl}^{-}$ & $\mathrm{CO}_{3}{ }^{2-}$ & $\mathrm{HCO}_{3}{ }^{-}$ & RAS & Dureza & Cátions & Aníons \\
\hline & (água) & $\mathrm{dS} \mathrm{m}^{-1}$ & \multicolumn{7}{|c|}{ mmolc L $^{-1}$} & $\mathrm{mg} \mathrm{L}^{-1}$ & \multicolumn{2}{|c|}{ mmolc L $^{-1}$} \\
\hline $\mathrm{A} 1$ & 7,71 & 0,57 & 0,33 & 3,40 & 0,50 & 2,60 & 040 & 2,40 & 4,2 & 65 & 5,0 & 5,4 \\
\hline A2 & 7,00 & 4,50 & 0,30 & 26,56 & 10,10 & 40,0 & 000 & 1,90 & 9,9 & 725 & 41,4 & 41,9 \\
\hline $\mathrm{A} 3$ & 7,14 & 2,65 & 0,33 & 15,16 & 4,70 & 23,0 & 0,00 & 2,10 & 7,7 & 390 & 23,3 & 25,1 \\
\hline
\end{tabular}

CE é a condutividade elétrica; RAS é a razão de absorção de sódio.

A cultura avaliada foi o Milho (Zea mays L.) hibrido AG 1051. A adubação constou de $10 \mathrm{~g}$ de Mono Amônio Fosfato por coluna, antes do plantio. Foram plantadas cinco sementes por coluna, das quais permaneceram apenas duas plantas até o final do crescimento vegetativo (40 dias após emergência), quando as plantas foram cortadas rente ao solo. Para determinação da massa seca as plantas foram secas em estufa por três dias a $65^{\circ} \mathrm{C}$ e, em seguida, foram moídas em moinho tipo Willey para determinação do teor dos nutrientes, nitrogênio $(\mathrm{N})$, fósforo $(\mathrm{P})$, potássio $(\mathrm{K})$, cálcio $(\mathrm{Ca})$ e magnésio $(\mathrm{Mg})$, da massa seca da parte aérea conforme metodologia apresentada em Carmo et al. (2000).

Os dados foram submetidos à análise de variância e Teste $\mathrm{F}(\mathrm{p}<0,05)$ para verificar a significância do efeito dos fatores e da sua interação. No caso de interação significativa foi verificado o efeito de doses de biochar em cada nível de salinidade da água. Após a análise de regressão dos fatores significativos, o modelo de melhor ajuste foi escolhido conforme o nível de significância e o coeficiente de determinação.

\section{RESULTADOS E DISCUSSÃO}

Em geral, tantos as doses de biochar como os níveis de salinidade da água de irrigação exerceram efeitos significativos $(\mathrm{p}<0,01)$ sobre as variáveis analisadas (Tabela 3). Da mesma maneira, em geral o efeito da interação entre doses de biochar e níveis de salinidade da água foi significativo para todas as variáveis nos três solos $(\mathrm{p}<0,01)$.

A massa seca da parte aérea (MSPA) do milho, no Argissolo, foi influenciada apenas pela dose de biochar, tendo aumentado de forma quadrática até a dose de 1,2\%, sendo $32 \%$ maior do que a testemunha sem biochar (Figura 1A). Isto está de acordo com Maia e Sohi (2010), que observaram aumento de $17 \%$ na massa seca de milho forrageiro com a adição de $30 \mathrm{tha}$

${ }^{1}$ de biochar, em relação ao tratamento sem biochar. Observa-se também que os valores de MSPA obtidos no Argissolo, que apresentava menor fertilidade (Tabela 1), foram inferiores aos obtidos no Cambissolo (Figura 1B), independente da água utilizada, e do que os obtidos nos Neossolo Flúvico (Figura 1C), com exceção da água de maior salinidade.

Quando se aplicou a água menos salina $\left(0,57 \mathrm{dS} \mathrm{m}^{-1}\right)$ no Cambissolo (Figura 1 B) e no Neossolo Flúvico (Figura 1 C) a a MSPA apresentou comportamento quadrático. No Cambissolo a menor MSPA ocorreu na dose de $0,8 \%$ de biochar, enquanto que no Neossolo Flúvico a maior MSPA ocorreu na dose de $0,6 \%$. As MSPA obtidas com a água menos salina superaram as obtida com a água mais salina e, também a MSPA obtida com a água de salinidade intermediária, com exceção da dose de 1,5\%. Neste sentido, Sousa et al. (2010) observaram redução na biomassa do milho com o aumento da CE da água de irrigação. 
Tabela 3. Resumo da análise de variância da Massa Seca da Parte Aérea e seus teores de nutrientes em milho recebendo águas salinas e doses de biochar em três tipos de solos da região Oeste do Rio Grande do Norte.

\begin{tabular}{|c|c|c|c|c|c|c|c|}
\hline \multirow[b]{2}{*}{ Fonte de variação } & \multirow[b]{2}{*}{ GL* } & \multicolumn{6}{|c|}{ Argissolo } \\
\hline & & MSPA & $\mathrm{N}$ & $\mathrm{P}$ & $\mathrm{K}$ & $\mathrm{Ca}$ & $\mathrm{Mg}$ \\
\hline & & \multicolumn{6}{|c|}{ Quadrados Médios } \\
\hline Dose & 3 & $448,47 * *$ & $20,87 *$ & $0,57 * *$ & $88,71 * *$ & $68,75^{* *}$ & $44,26^{* *}$ \\
\hline Água & 2 & $8,85^{\text {ns }}$ & $68,54 * *$ & $0,19^{\text {ns }}$ & $39,11 * *$ & $0,03^{\mathrm{ns}}$ & $14,51 * *$ \\
\hline Dose $x$ água & 6 & $75,53^{\mathrm{ns}}$ & $29,51 * *$ & $1,40^{* *}$ & $6,62 * *$ & $1,51 * *$ & $2,025 * *$ \\
\hline Erro & 36 & 68,87 & 48,40 & 0,03 & 0,24 & 0,203 & 0,10 \\
\hline CV (\%) & & 17,13 & 9,29 & 23,38 & 16,26 & 13,75 & 23,55 \\
\hline \multirow[t]{2}{*}{ Média Geral } & & 48,44 & 23,69 & 0,78 & 3,02 & 3,23 & 1,34 \\
\hline & & \multicolumn{6}{|c|}{ Cambissolo } \\
\hline Dose & 3 & $2456,15^{* *}$ & $89,44 * *$ & $0,46^{* *}$ & $3,60 * *$ & $12,92 * *$ & $12,92 * *$ \\
\hline Água & 2 & $22817,07 * *$ & $64,19 * *$ & $0,12 * *$ & $0,20^{\text {ns }}$ & $4,71 * *$ & $4,71 * *$ \\
\hline Dose $\mathrm{x}$ água & 6 & $3624,74 * *$ & $238,07 * *$ & $0,13 * *$ & $3,90 * *$ & $2,69 * *$ & $2,69 * *$ \\
\hline Erro & 36 & 111,85 & 79,49 & 0,008 & 0,64 & 0,41 & 0,418 \\
\hline CV (\%) & & 10,31 & 10,94 & 17,46 & 19,66 & 17,92 & 17,92 \\
\hline \multirow[t]{2}{*}{ Média Geral } & & 102,55 & 25,78 & 0,51 & 4,08 & 3,56 & 1,13 \\
\hline & & \multicolumn{6}{|c|}{ Neossolo flúvico } \\
\hline Dose & 3 & $29,67^{\mathrm{ns}}$ & $204,96^{* *}$ & $0,35 * *$ & $7,57 * *$ & $2,92 * *$ & $0,50 * *$ \\
\hline Água & 2 & $6865,98^{* *}$ & $28,55^{* *}$ & $0,04 * *$ & $2,85^{* *}$ & $11,51 * *$ & $0,52 * *$ \\
\hline Dose $\mathrm{x}$ água & 6 & $467,27 * *$ & $20,66^{* *}$ & $0,09 * *$ & $3,48 * *$ & $3,17 * *$ & $0,81 * *$ \\
\hline Erro & 36 & 34,47 & 35,50 & 0,001 & 0,27 & 0,03 & 0,001 \\
\hline $\mathrm{CV}(\%)$ & & 9,06 & 13,40 & 7,08 & 8,47 & 6,87 & 8,25 \\
\hline Média Geral & & 64,83 & 14,06 & 0,45 & 6,17 & 2,36 & 2,40 \\
\hline
\end{tabular}

$\mathrm{GL}=$ graus de liberdade; MSPA = massa seca da parte aérea do milho; $\mathrm{CV}=$ coeficiente de variação.

Figura 1. Massa seca da parte aérea do milho em Argissolo (A), Cambissolo (B) e Neossolo Flúvico (C) recebendo diferentes doses de biochar e níveis de salinidade da água
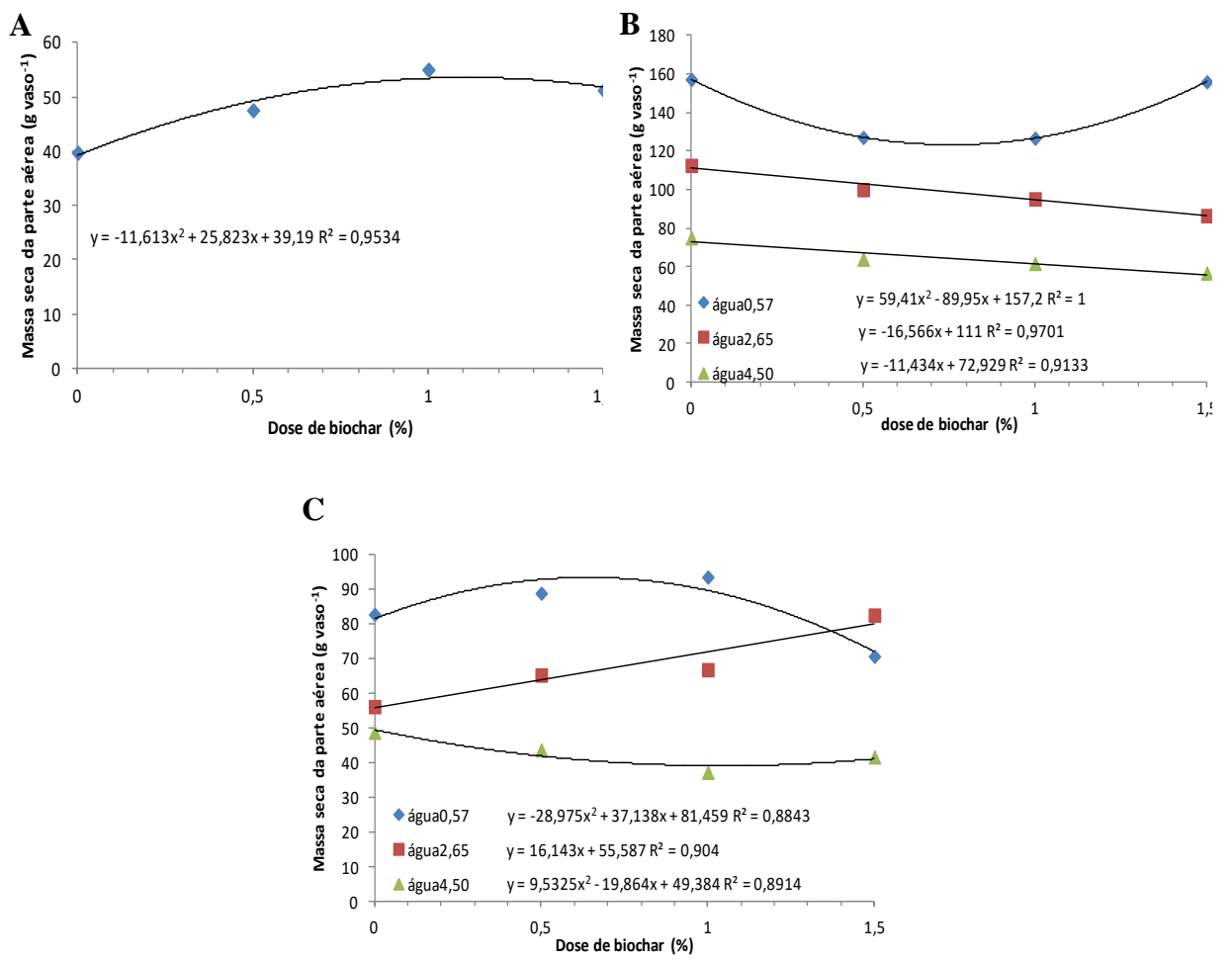

A aplicação da água mais salina $\left(4,50 \mathrm{dS} \mathrm{m}^{-1}\right)$, tanto no Cambissolo como no Neossolo Flúvico, causou tendência de diminuição na MSPA com a dose de biochar. Essa diminuição foi linear no Cambissolo, sendo de $15 \%$ na MSPA entre a dose

zero e a dose de $1,5 \%$ de biochar, enquanto que no Neossolo a mínima MSPA foi obtida na dose de 1,0\% de biochar. A aplicação da água de salinidade intermediária $\left(2,65 \mathrm{dS} \mathrm{m}^{-1}\right)$ resultou em efeito linear sobre a MSPA, havendo decréscimo de 
$23 \%$ entre as doses zero e $1,5 \%$ de biochar no Cambissolo e aumento de $42 \%$ entre as mesmas doses, no Neossolo.

O benefício do biochar para a MSPA indica mitigação do efeito da salinidade da água no Argissolo, independente da água utilizada, e no Neossolo Flúvico para a água de salinidade intermediária. Isso se deve pelo biochar, com aumento da disponibilidade de água no solo e melhor condição hídrica das plantas, pela redução nos efeitos osmóticos e toxicidade iônica dos sais (THOMAS et al., 2013). Segundo Akhtar et al. (2015), devido a sua alta capacidade de adsorção, o biochar reduz a absorção de sódio pelas plantas por meio de ligação transitória com $\mathrm{Na}^{+}$, causando diminuição no estresse osmótico pelo aumento no teor de água do solo, e pela liberação de nutrientes minerais como $\mathrm{K}^{+}, \mathrm{Ca}^{++}$e $\mathrm{Mg}^{++}$para a solução do solo.

O melhor efeito do biochar sobre a MSPA do milho ocorreu no Argissolo, confirmando Jeffery et al. (2011) para quem os maiores efeitos ocorrem em solos mais arenosos e mais ácidos. Um comportamento inverso foi observado para a MSPA, que diminuiu no Cambissolo e aumentou no Neossolo Flúvico para a água de menor salinidade, com ponto de inflesão em nível semelhante de salinidade da água. Para a água de salinidade intermediária a MSPA diminuiu no Cambissolo e aumentou no Neossolo.

Isso pode ser devido a que, no Cambissolo, que possuía maior teor de potássio e de argila, quando se aplicou a água menos salina, o biochar adicionou nutrientes e melhorou a estrutura do solo e a CTC (UZOMA et al., 2011). Enquanto que no Neossolo, onde se destaca o teor de silte, recebendo água de salinidade intermediária o benefíco à MSPA pode se dever à melhoria na condiçâo física do solo proporcionada pelo biochar. Isso é apoiado por Thomas et al. (2013), para quem o biochar diminui os efeitos negativos da salinidade pela melhoria na estrutura do solo, e Akhtar et al. (2015) ao destacar a absorção de íons como o Na pelo biochar. A menor MSPA no Neossolo recebendo a água menos salina e maior dose de biochar pode se dever à diminuição na porosidade do solo por partículas do biochar (LIU et al., 2017).

A influência da dose e da matéria prima do biochar foi citada por Rajkovich et al. (2012), que obtiveram aumento de $30 \%$ na biomassa do milho, quando usaram biochar feito de esterco animal e de $43 \%$ para biochar de palha de milho, enquanto que ocorreu diminuição de $92 \%$ com biochar feito de restos de alimentos. Segundo os autores, o benefício ao crescimento das plantas nas menores doses $(0,2$ e $0,5 \%)$ se deveu a maiores teores de $\mathrm{N}, \mathrm{P}, \mathrm{K}$ e $\mathrm{Mg}$ no solo, enquanto o prejuízo nas maiores doses $(2,0$ e $7,0 \%)$ se deveu ao maior teor de Na. Nesse sentido, Araújo et al. (2010) destacam o efeito tóxico de íons como o $\mathrm{Na}^{+}$e $\mathrm{Cl}^{-}$sobre a fixação líquida de carbono e produção de fotoassimilados.

Quanto ao teor de nitrogênio, a aplicação da água não salina $\left(0,57 \mathrm{dS} \mathrm{m}{ }^{-1}\right)$ indica o efeito individual do biochar, que reduziu linearmente $(29 \%)$ o teor de nitrogênio entre as doses zero e 1,5\% no Argissolo (Figuras 2A), apesar deste teor ser maior que os obtidos com os outros níveis de salinidade, exceto na maior dose. Isto é devido a retenção pelo biochar do nitrogênio no solo, diminuindo sua disponibilidade (STEINER et al., 2010). Isso pode trazer benefício econômico e ambiental, pois reduz emissões de $\mathrm{N}_{2} \mathrm{O}$ e perdas de $\mathrm{N}$ por lixiviação (NÓBREGA, 2011) e se aumentar a eficiência de uso do $\mathrm{N}$ pelas culturas (CHAN et al., 2007). No Cambissolo (Figura 2B), observou-se aumento quadrático do teor de nitrogênio na MSPA até a dose de $1 \%$ de biochar, enquanto que no Neossolo Flúvico (Figura 2C) ocorreu redução quadrática do teor de nitrogênio na MSPA até a dose de $0,8 \%$ de biochar, apesar de que na maior dose de biochar o teor de nitrogênio ainda foi $27 \%$ menor do que na dose zero.

Figura 2. Teor de nitrogênio na massa seca da parte aérea do milho em Argissolo (A), Cambissolo (B) e Neossolo Flúvico (C) sob doses de biochar e níveis de salinidade da água.
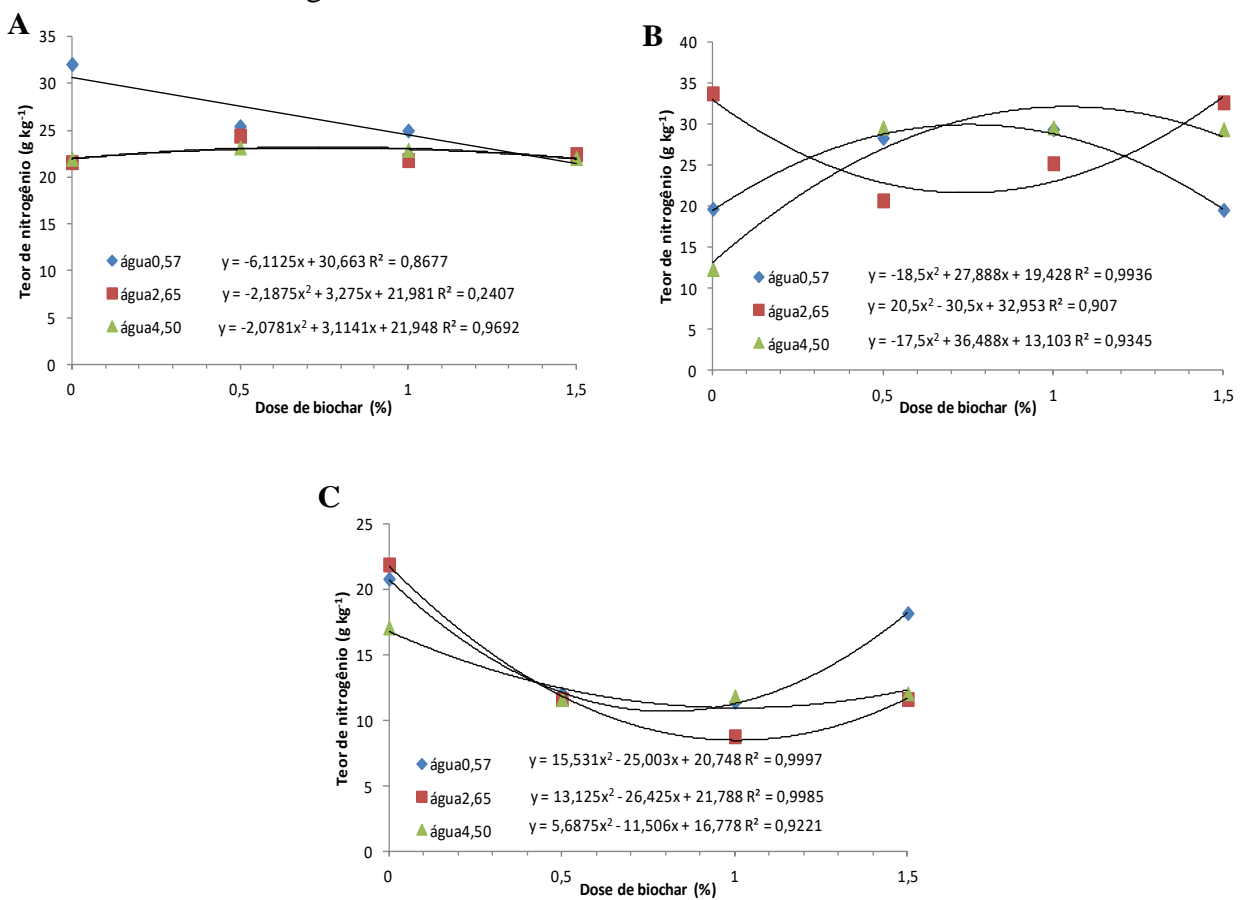

Revista Verde, v.13, n.4, p.672-682, 2018 
Usando-se a água com salinidade de $2,65 \mathrm{dS} \mathrm{m}^{-1}$ no Argissolo, o teor de $\mathrm{N}$ aumentou até a dose de $0,7 \%$ de biochar, a partir da qual ele diminuiu até a maior dose. No Neossolo Flúvico, o teor de nitrogênio na MSPA do milho diminuiu até a dose de $1,1 \%$ de biochar, enquanto que no Cambissolo o teor de nitrogênio diminuiu até a dose de $0,7 \%$ de biochar.

Usando-se a água de maior salinidade $\left(4,50 \mathrm{dS} \mathrm{m}^{-1}\right)$ no Argissolo, o teor de o teor de $\mathrm{N}$ nas plantas aumentou até a dose de $0,7 \%$ de biochar, enquanto que, no Cambissolo aumentou até a dose de $0,7 \%$ e no Neossolo Flúvico o $\mathrm{N}$ diminuiu até a dose de 1,0 de biochar. No Neossolo Flúvico a aplicação de biochar teve pequeno efeito sobre a absorção de nitrogênio pelas plantas, que é um dos principais efeitos iônicos de toxicidade por sais, segundo Lewis et al. (1989). Segundo Farooq et al. (2015), a absorção e translocação de nitrogênio são muito inibidas pelo estresse salino, com redução no teor de nitrogênio em diferentes partes das plantas de milho. Os autores citam trabalho no qual aumento gradual de sais na água de irrigação causa redução na absorção de nitrogênio até a $\mathrm{CE}$ da água de 6 $\mathrm{dS} \mathrm{m}{ }^{-1}$.

No argissolo o maior efeito das doses de biochar foi reduzir a absorção de $\mathrm{N}$ nas plantas recebendo a água menos salina, enquanto que com as águas mais salinas o biochar pode ter retido o excesso de sais. No Cambissolo e no Neossolo Flúvico ocorreram efeitos contrários das doses de biochar sobre o teor de $\mathrm{N}$ na MSPA, principalmente recebendo as águas de 0,57 e 4,50 ds $\mathrm{d}^{-1}$; o teor de $\mathrm{N}$ aumentou no Cambissolo até as doses respectivas de $1 \%$ e $1,1 \%$, e diminuiu no Neossolo
Flúvico até as doses de $0,8 \%$ e $1,0 \%$.

$\mathrm{O}$ efeito do biochar no Cambissolo pode ser devido à melhoria na estrutura do solo, possibilitando maior exploração do solo pelas raízes, ou pela adição de $\mathrm{Ca}$ e $\mathrm{K}$ ao solo, que pode melhorar a eficiência de uso do nitrogênio em plantas sob estresse salino, segundo Lewis et al. (1989). No Neossolo Flúvico o problema seria o preenchimento pelo biochar dos poros do solo, que já possui teores mais altos de silte. A influência do tipo de solo foi discutida por Zhang et al. (2016) que observaram agravamento da salinidade com a aplicação de biochar, dependendo da matéria prima de biochar e do tipo de solo.

Teores adequados de nitrogênio nas plantas, considerando os valores entre 27,5 e 32,5 $\mathrm{g} \mathrm{kg}^{-1}$ adotados por Moreira et al. (2014), ocorreram no Argissolo, com a água não salina e doses mais baixas de biochar, no Cambissolo com as maiores doses de biochar para as águas salinas e em doses intermediárias de biochar para a água não salina.

A aplicação no Argissolo da água menos salina $(0,57 \mathrm{dS}$ $\mathrm{m}^{-1}$ ) causou diminuição no teor de $\mathrm{P}$ nas plantas até a dose de $0,5 \%$ de biochar (Figura 3A). Com esta água, na maior dose de biochar, o teor de $\mathrm{P}$ foi maior do que com águas mais salinas e foi $135 \%$ maior do que na dose zero. No Cambissolo, o teor de $\mathrm{P}$ nas plantas aumentou até a dose de 1,5\% (Figura 3B) na qual o teor foi $64 \%$ maior do que na dose zero, enquanto que no Neossolo Flúvico ocorreu aumento até a dose de 1\% (Figura 3C), diminuindo um pouco até a dose de 1,5\%.

Figura 3. Teores de fósforo na massa seca da parte aérea do milho em Argissolo (A), Cambissolo (B) e Neossolo Flúvico (C) sob doses de biochar e níveis de salinidade da água.

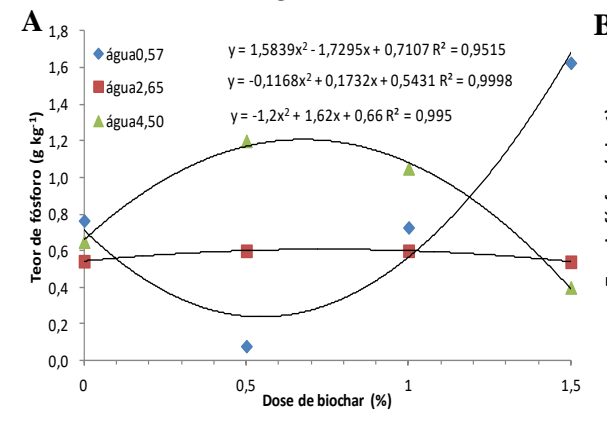

B 0,9 *água0, $57 y=0,291 x^{2}-0,2311 x+0,4414 R^{2}=0,9999$
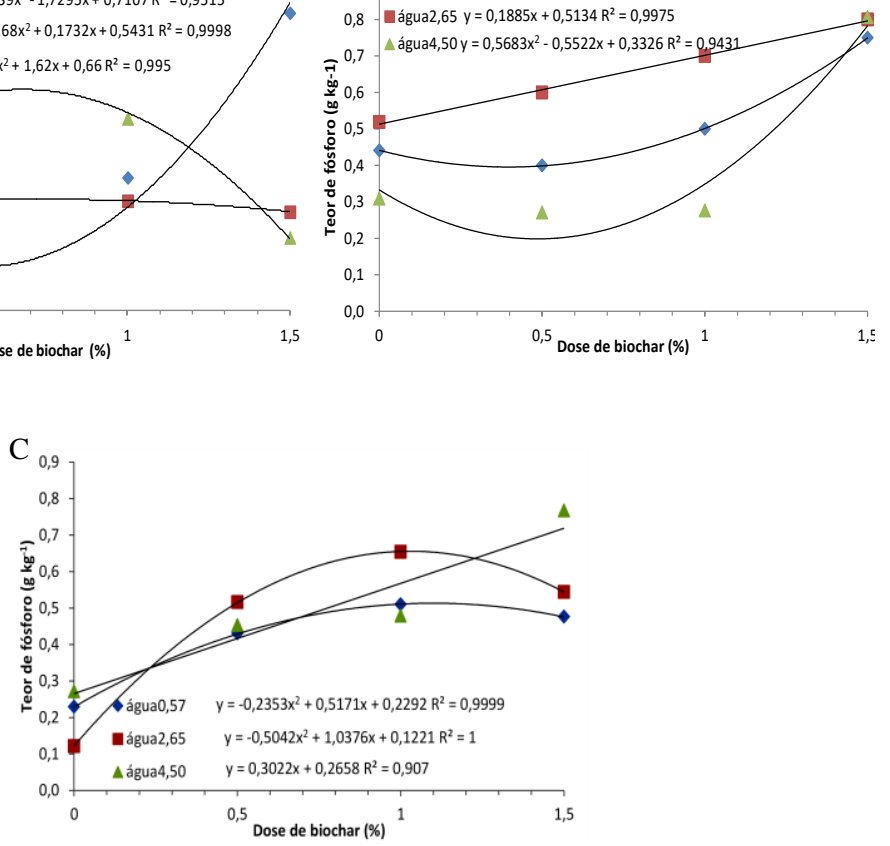

Quando se usou água com salinidade de $4,50 \%$ no Argissolo, o teor de $\mathrm{P}$ aumentou até a dose de $0,7 \%$ de biochar, enquanto que no Neossolo Flúvico o aumento foi linear (160\%) entre as doses zero e $1,5 \%$ de biochar. No cambissolo, o teor de P nas plantas diminuiu até a dose de $0,5 \%$ de biochar, porém foi semelhante para as três águas na maior dose de biochar. O teor 
de $\mathrm{P}$ nas plantas aumentou até a dose de $0,8 \%$ de biochar, quando se usou a água com de $2,65 \%$ no Argissolo; no Cambissolo o aumento foi linear de $64 \%$ entre as doses zero e $1,5 \%$ e, no Neossolo Flúvico, ocorreu aumento até a dose de $1 \%$.

Observou-se tendência de aumento no teor de $\mathrm{P}$ nas plantas com a dose de biochar em todos os solos e níveis de salinidade da água. Apesar disso, não se observou teores adequados de fósforo nas plantas, considerando os valores entre 1,9 e $3,5 \mathrm{~g} \mathrm{~kg}^{-1}$ adotados por Moreira et al. (2014).O aumento foi mais acentuado com a água menos salina no Argissolo, com todas as águas no Cambissolo e com a água de $4,50 \mathrm{dS} \mathrm{m}^{-1}$ no Neossolo Flúvico. Segundo Sharpley et al. (1992), a concentração de $\mathrm{P}$ nos tecidos das plantas pode ser reduzida de $20 \%$ a $50 \%$, em ambiente salino, sem sintomas de deficiência de $\mathrm{P}$ nas plantas. $\mathrm{O}$ fósforo é um dos nutrientes mais importantes para a formação de grãos do milho, mas limita a produtividade em solos tropicais porque sua mobilidade e fixação nos coloides do solo limitam a absorção pelas plantas (MACHADO; SOUZA, 2012). Segundo Madari et al. (2006), o biochar disponibiliza no solo o $\mathrm{P}$ ligado à matéria orgânica, mas não o $\mathrm{P}$ em ligado com argilominerais do solo.
A aplicação de biochar melhora a disponibilidade de $\mathrm{P}$ para as plantas. Neste sentido, Gundale e De Luca (2007) obtiveram aumento no teor de $\mathrm{P}$ com aplicação de $2 \%$ de biochar em solo arenoso e Petter e Madari. (2012) obtiveram aumento de $17 \%$ com a dose $32 \mathrm{t} \mathrm{ha}^{-1}$ em relação à testemunha. $\mathrm{O}$ benefício para as culturas se deve tanto ao efeito indireto do biochar sobre a disponibilidade de $\mathrm{P}$ no solo como ao $\mathrm{P}$ contido na fração cinzas do biochar (SOHI et al., 2010). Entretanto, Lehmann et al. (2003) e Carvalho et al. (2013) não observaram melhoria na disponibilidade de $\mathrm{P}$ pela aplicação de biochar.

A aplicação da água não salina $\left(0,57 \mathrm{dS} \mathrm{m}^{-1}\right)$ no Argissolo causou diminuição no teor de potássio nas plantas até a dose de $0,5 \%$ de biochar (Figura 4A), a partir da qual os teores de $\mathrm{K}$ aumentaram até a doses de $1,5 \%$ e foram $127 \%$ maiores do que na dose zero. $\mathrm{O}$ teor de $\mathrm{K}$ nas plantas foi maior na maior dose de biochar do que o teor obtido com as águas de maior salinidade. No Cambissolo (Figura 4B) e no Neossolo Flúvico (Figura 4C), o uso desta água fez com que o teor de potássio nas plantas aumentasse até as doses de $0,85 \%$ e $1,0 \%$ de biochar, respectivamente, nos dois casos o teor de $\mathrm{K}$ na maior dose de biochar ainda foi superior ao teor na dose zero.

Figura 4. Teores de potássio na massa seca da parte aérea do milho em Argissolo (A), Cambissolo (B) e Neossolo Flúvico (C) sob doses de biochar e níveis de salinidade da água.

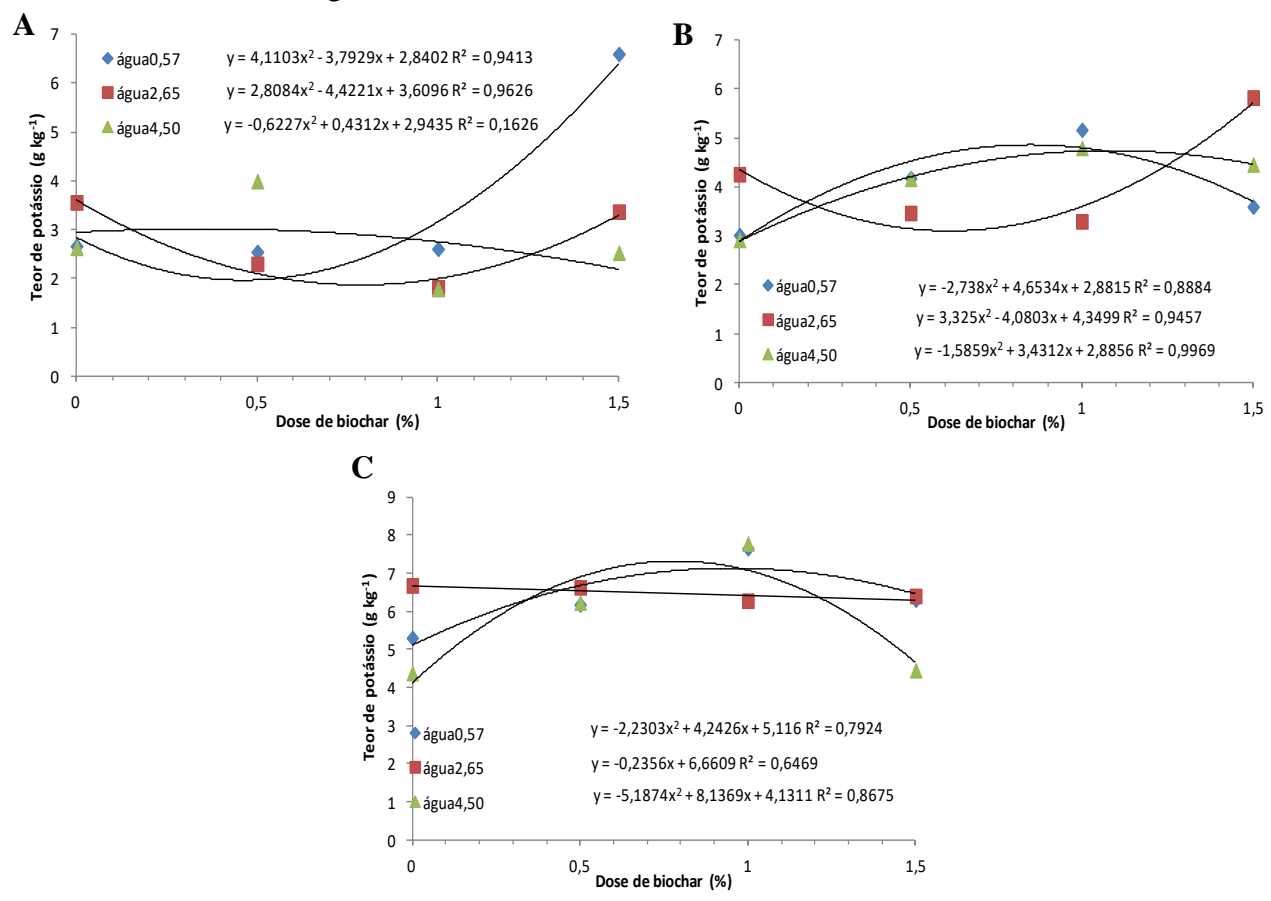

Quando se usou a água de $2,65 \mathrm{dS} \mathrm{m}^{-1}$ o teor de $\mathrm{K}$ nas plantas diminuiu até a dose de $0,8 \%$ de biochar no Argissolo, e até a dose $0,6 \%$ no Cambissolo, enquanto que, no Neossolo Flúvico a diminuição foi linear $(5 \%)$ entre a dose zero e a dose de $1,5 \%$. Usando-se a água de maior salinidade $\left(4,50 \mathrm{dS} \mathrm{m}^{-1}\right) \mathrm{o}$ efeito do biochar foi de aumentar o teor de potássio nas plantas até a dose de $0,5 \%$ de biochar no Argissolo, $1,1 \%$ no Cambissolo e 0,8\% no Neossolo Flúvico. A partir destas doses, o teor de $\mathrm{K}$ nas plantas diminuiu até a dose de 1,5\% de biochar, com maior decréscimo no Neossolo Flúvico, porém mesmo assim o teor de $\mathrm{K}$ foi um pouco superior ao teor na dose zero. Ocorre redução no teor de potássio nas folhas do milho sob estresse salino devido à interferência do sódio na absorção do potássio; tal redução depende do genótipo de milho (FAROOQ et al., 2015). Os maiores efeitos do biochar ocorreram no Argissolo, recebendo a água menos salina, e no Cambissolo com a água com salinidade de $2,65 \mathrm{dS} \mathrm{m}^{-1}$, cujo teor de potássio aumentou $24 \%$ entre as doses zero e $1,5 \%$ de biochar.

Os teores de potássio nas plantas, em todas as situações, ficaram bem abaixo dos valores considerados adequados para o 
milho adotados por Moreira et al. (2014), que variam entre 17,5 e $29,7 \mathrm{~g} \mathrm{~kg}^{-1}$. O potássio é nutriente limitante para as culturas e seu baixo teor em relação a outros cátions trocáveis provoca desequilíbrio nutricional, afetando sua absorção (MALAVOLTA, 2006). Neste sentido, Jeffery et al. (2011) destacam que a maior disponibilidade de $\mathrm{K}$ no solo é um efeito importante da aplicação do biochar sobre a produtividade das culturas. O aumento no teor de potássio disponível para as plantas devido ao biochar foi observado por Madari et al. (2006) e Chan et al. (2007).

No Argissolo (Figura 5A) e no Cambissolo (Figura 5B), quando se aplicou a água menos salina $\left(0,57 \mathrm{dS} \mathrm{m}^{-1}\right)$, os teores de cálcio nas plantas diminuiram até as doses de $0,5 \%$ e $0,2 \%$ de biochar, respectivamente, e os melhores resultados ocorreram na maior dose aplicada, com aumentos em relação à dose zero de $75 \%$ no Argissolo e de $73 \%$ no Cambissolo. Enquanto isso, no Neossolo Flúvico (Figura 5C) o teor de cálcio nas plantas cresceu até a dose de $0,7 \%$ de biochar.

Quando se usou a água com salinidade de $2,65 \mathrm{dS} \mathrm{m}^{-1}$, o teor de cálcio nas plantas apresentou aumento linear entre a dose zero e de 1,5\% de biochar de $81 \%$ Argissolo e de $115 \%$ no Neossolo flúvico. Enquanto isso, no Cambissolo apesar do efeito ser quadrático o aumento no teor de cálcio nas plantas foi de $74 \%$ entre a menor e a maior dose. Quando se usou água com salinidade de 4,50 dS m${ }^{-1}$, no Argissolo e no Neossolo Flúvico, o teor de cálcio nas plantas diminuiu até a dose de 0,4\% de biochar, enquanto que no Cambissolo o teor de cálcio nas plantas aumentou até a dose $1,1 \%$ de biochar.

No Argissolo, os teores de cálcio nas plantas foram semelhantes na maior dose de biochar para as três níveis de salinidade da água. Os melhores efeitos das doses de biochar sobre o teor de cálcio nas plantas ocorreram quando se usou a água com salinidade de $2,65 \mathrm{dS} \mathrm{m}^{-1}$, principalmente no Neossolo Flúvico. Esse efeito é importante, porque segundo Farooq et al. (2015), a acumulação do sódio presente na água prejudica a nutrição por cálcio, principalmente em folhas jovens de milho. Um dos principais problemas é a menor expansão das folhas do milho, pois o cálcio é necessário para a integridade das membranas celulares.

Em geral, os teores de cálcio nas plantas ficaram entre os valores considerados adequados para o milho, que variam entre 2,3 e 4,0 $\mathrm{g} \mathrm{kg}^{-1}$ segundo Moreira et al. (2014). A exceção foi quando se usou água não salina no Neossolo Flúvico, destacando a contribuição das águas salinas e do biochar em fornecer cálcio. Aumentos no teor de cátions trocáveis com aplicação de biochar também foram obtidos por Chan et al. (2007), usando doses altas, por Carvalho et al. (2013), que observaram aumento linear dos teores de $\mathrm{Ca}$ e $\mathrm{Mg}$ no solo com o aumento da dose de biochar e por Petter e Madari (2012) que obtiveram aumento no teor de cálcio no solo com dose de $32 \mathrm{t}$ $\mathrm{ha}^{-1}$ de biochar em relação à testemunha. Petter (2010) aplicou biochar em soja e arroz no cerrado e observou aumento no teor de $\mathrm{Ca}$ e na eficiência de uso dos nutrientes.

Figura 5. Teores de cálcio na massa seca da parte aérea do milho em Argissolo (A), Cambissolo (B) e Neossolo Flúvico (C) sob doses de biochar e níveis de salinidade da água.
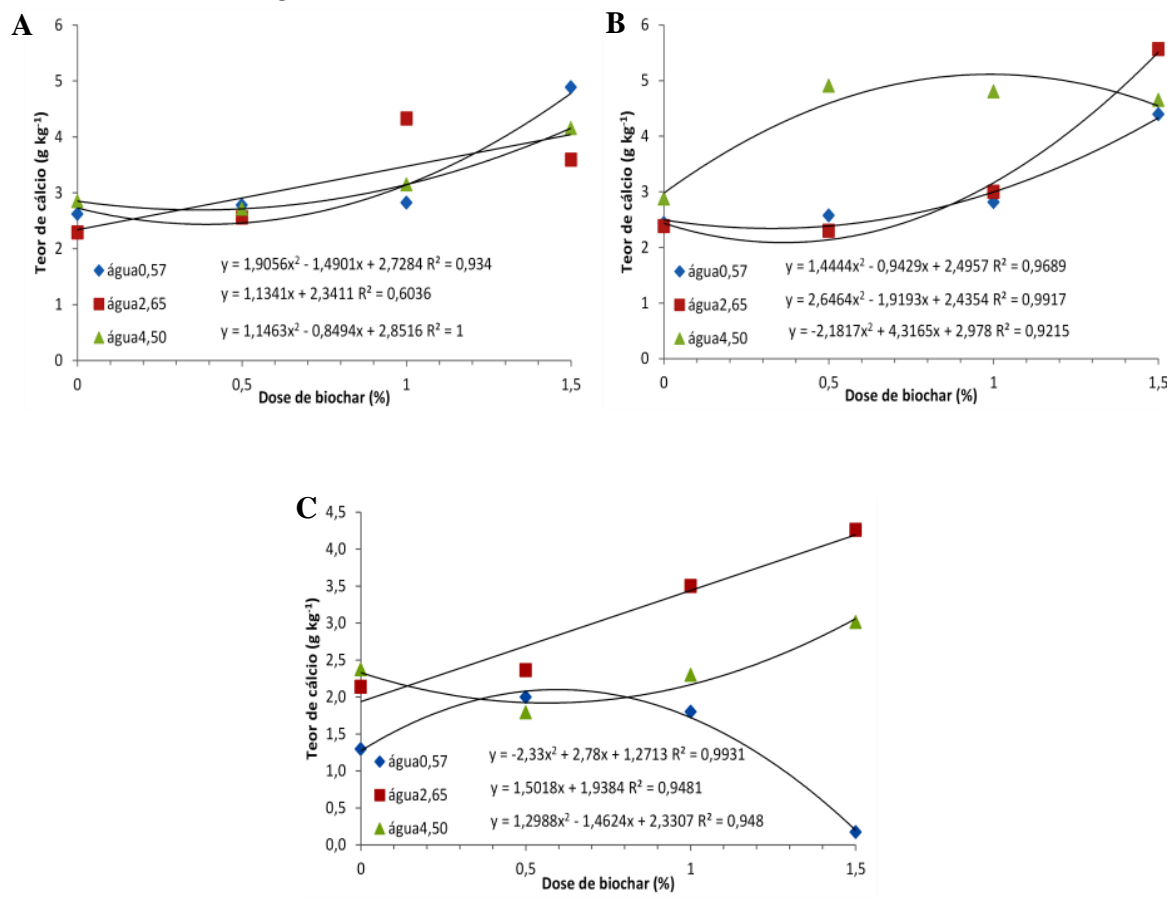

Quando se aplicou a água de menor salinidade $\left(0,57 \mathrm{dS} \mathrm{m}^{-}\right.$ ${ }^{1}$ ) no Argissolo (Figura 6A) o teor de magnésio nas plantas aumentou de forma quadrática (212\%) entre a dose zero e a dose de 1,5\% de biochar. Enquanto isso, no Cambissolo (Figura 6B) e no Neossolo Flúvico (Figura 6C) os teores de magnésio nas plantas aumentaram até as doses de biochar de $1,0 \%$ e 0,8 $\%$, respectivamente.

No caso da aplicação da água mais salina $\left(2,65 \mathrm{dS} \mathrm{m}^{-1}\right) \mathrm{o}$ teor de magnésio nas plantas aumentou até a dose de 0,8\% de biochar no Argissolo e até 0,5\% no Neossolo Flúvico. Enquanto 
que no Cambissolo o teor o teor de magnésio aumentou de forma quadrática (181\%) entre a dose zero e a dose de $1,5 \%$ de biochar.

Quando se usou água com salinidade de 4,50 dS m $\mathrm{m}^{-1}$ no Argissolo e no Cambissolo os teores de magnésio nas plantas aumentaram até as doses de biochar de 0,3 e $1,0 \%$ respectivamente, enquanto que no Neossolo Flúvico o teor de magnésio nas plantas aumentou $28 \%$ entre as dose zero e $1,5 \%$ de biochar.

Os melhores efeitos do biochar sobre os teores de magnésio nas plantas ocorreram com o uso da água menos salina no Argissolo e com a água com salinidade de $4,50 \mathrm{dS} \mathrm{m}^{-1}$ no Cambissolo e no Neossolo Flúvico. No Neossolo Flúvico e no Cambissolo, mesmo com a aplicação de águas salinas, foram observados aumentos dos teores de $\mathrm{Mg}$ das plantas de milho devidos à aplicação de biochar. Isso é importante, porque segundo Farooq et al. (2015), o teor de magnésio em folhas e raízes do milho diminuem muito em condições de salinidade e de deficiência de potássio, com redução muito maior se estes estresses ocorrem em conjunto.

Os teores de magnésio nas plantas cultivadas no Neossolo Flúvico estavam dentro da faixa adequada para o milho, segundo Moreira et al. (2014), que varia entre 1,5 e 4,0 $\mathrm{g} \mathrm{kg}^{-1}$. No Cambissolo, os teores adequados somente foram obtidos com a adição de biochar quando se usou as águas mais salinas, enquanto que no Argissolo eles foram alcançados com a maior dose de biochar quando se usou água não salina. Aumento linear dos teores $\mathrm{Mg}$ no solo com o aumento da dose de biochar foi observado por Carvalho et al. (2013), enquanto Melo (2016) atribui à aplicação de biochar a manutenção dos teores de $\mathrm{Mg}$ no solo após dois cultivos de feijão-caupi. Segundo Akhtar et al. (2015), devido à alta capacidade de adsorção, o biochar se liga transitoriamente com $\mathrm{Na}^{+}$, reduzindo sua absorção pelas plantas, amenizando o estresse osmótico porque aumenta o teor de água do solo e libera nutrientes como $\mathrm{K}^{+}, \mathrm{Ca}^{++}$e $\mathrm{Mg}^{++}$para a solução do solo.

Figura 6. Teores de magnésio na massa seca da parte aérea do milho em Argissolo (A), Cambissolo (B) e Neossolo Flúvico (C) sob doses de biochar e níveis de salinidade da água.
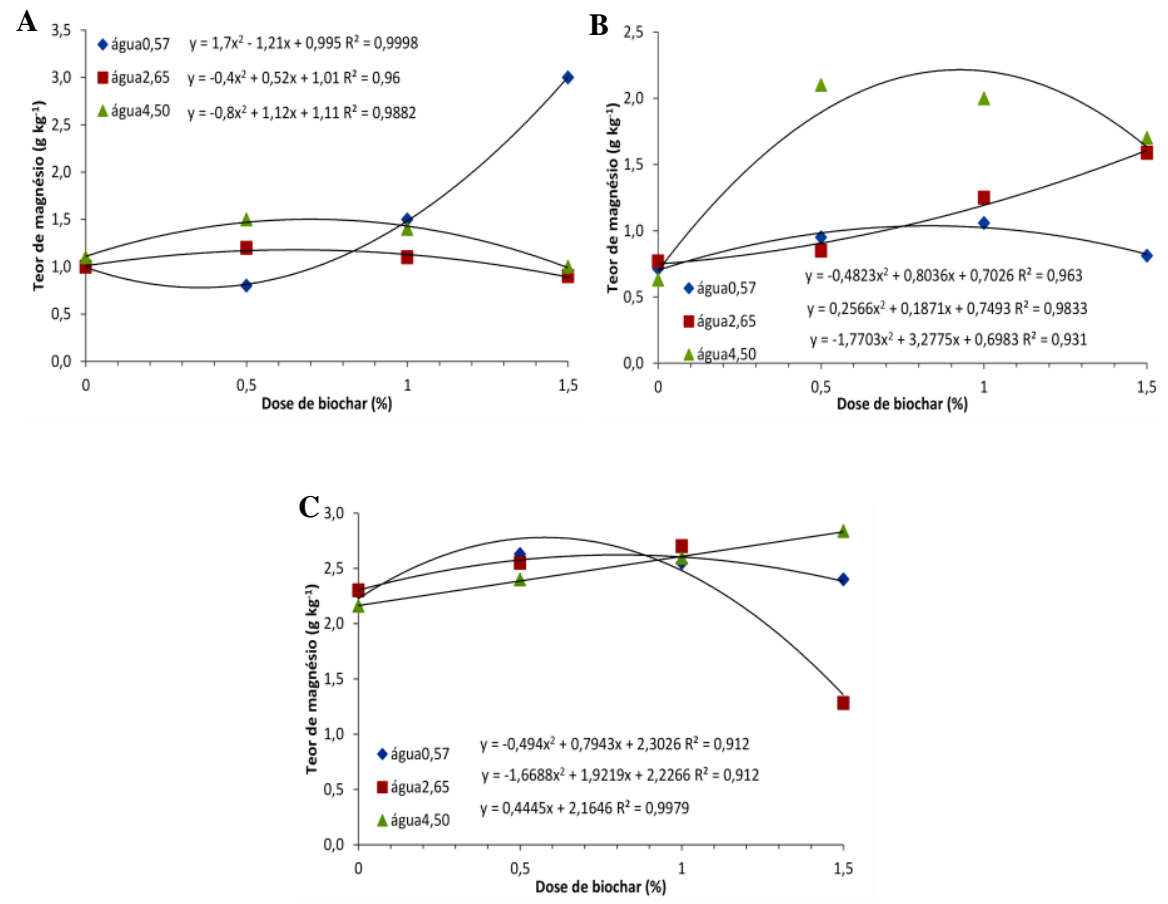

\section{CONCLUSÕES}

O efeito significativo da aplicação de biochar sobre a massa seca da parte aérea do milho e seus teores de nutrientes indica que ele pode mitigar a salinidade da água de irrigação.

O benefício da aplicação de biochar em mitigar os efeitos da salinidade da água de irrigação depende da dose aplicada e do tipo de solo.

\section{REFERÊNCIAS}

AKHTAR, S. S.; ANDERSEN, M. N.; LIU, F. Residual effects of biochar on improving growth, physiology and yield of wheat under salt stress. Agricultural Water Management, v. 158, n. 1, p. 61-68, 2015. 10.1016/j.agwat.2015.04.010

ARAÚJO, C.A.S.; RUIZ, H.A.; CAMBRAIA, J. NEVES, J.C.L.; FREIRE, M.B.G.S.; FREIRE, F.J. Seleção varietal de Phaseolus vulgaris quanto à tolerância ao estresse salino com base em variáveis de crescimento. Revista Ceres, v. 57, n.1, p. 132-139, 2010. 10.1590/S0034-737X2010000100021.

AYERS, R.S.; WESTCOT, D.W. A qualidade da água na agricultura. Campina Grande: UFPB, 1991. 218p. Estudos FAO: Irrigação e Drenagem.

BENITES, W. M.; TEIXEIRA, W. G.; REZENDE, M. E.; PIMENTA, A. S. Utilização de carvão e subprodutos da 
carbonização vegetal na agricultura: aprendendo com as terras pretas de índio. In: TEIXEIRA, W. G.; KERN, D. C.; MADARI, B. E.; LIMA, H. N.; WOODS, W. As Terras Pretas de índio da Amazônia: sua caracterização e uso deste conhecimento na criação de novas áreas. Manaus: Embrapa Amazônia Ocidental, 2009.p.286- 297.

CARMO, C. A. F. S.; ARAÚJO, W. S.; BERNARDI, A. C. C.; SALDANHA, M. F. C. Métodos de análise de tecidos vegetais utilizados na Embrapa Solos. Rio de Janeiro: Embrapa Solos, 2000. 41 p. (Embrapa Solos. Circular Técnica; 6).

CARVALHO, M. T. M.; MADARI, B. E.; BASTIAANS, L.; VAN OORT. P. A. J.; HEINEMANN, A. B.; SILVA, M. A. S.; MAIA, A. H. N.; MEINKE, H. Biochar improves soil fertility of a clay soil in the Brazilian Savannah: short term effects and impact on rice yield. Journal of Agriculture and Rural Development in the Tropics and Subtropics, v. 114, n. 2, p. 101 107, 2013. http://nbn-resolving.de/urn:nbn:de:hebis:342013081343330

CHAN, K. Y.; VAN ZWIETEN, L.; MESZAROS, I.; DOWNIE, A.; JOSEPH, S. Agronomic values of greenwaste biochar as a soil amendment. Soil Research, v. 45, n. 8, p. 629634, 2007. 10.1071/SR07109 DOI: 10.1071/SR07109

EKEBAFE, M. O.; EKEBAFE, L. O.; MALIKI, M. Utilisation of biochar and superabsorbent polymers for soil amendment. Science Progress, v. 96, n. 1, p.85-94, 2013. 10.3184/003685013X13587941096281

EMBRAPA - Empresa Brasileira de Pesquisa Agropecuária. Centro Nacional de Pesquisas de Solos. Manual de métodos de análises de solos. 2.ed. Rio de Janeiro: Embrapa Solos, 2011. $230 \mathrm{p}$.

FAROOQ, M.; HUSSAIN, M.; WAKEEL, A.; SIDDIQUE, K. H. M. Salt stress in maize: effects, resistance mechanisms, and management. A review. Agronomy for Sustainable Development, v. 35, n. 2, p. 461-481, 2015. 10.1007/s13593015-0287-0

FEIJÃO, A. R.; MARQUES, E. C.; SILVA, J. C. B.; LACERDA, C. F.; PRISCO, J. T.; GOMES-FILHO, E. Nitrato modula os teores de cloreto e compostos nitrogenados em plantas de milho submetidas à salinidade. Bragantia, v. 72, n. 1, p.10-19, 2013. 10.1590/S0006-87052013005000019

FAO. The state of the world's land and water resources for food and agriculture (SOLAW) - Managing systems at risk. Rome: Food and Agriculture Organization of the United Nations; London: Earthscan, 2011. 285 p.

FORNASIERI FILHO, D. Manual da cultura do milho. Jaboticabal: FUNEP, 2007. 576 p.

GUNDALE, M. J.; DE LUCA, T. H. Charcoal effects on soil solution chemistry and growth of Koeleria macrantha in the ponderosa pine/Douglas-fir ecosystem. Biology and Fertility of
Soils, v. 43, n. 3, p. 303-311. 2007. 10.1007/s00374-006-0106-5

HOLANDA, J. S.; AMORIM, J. R. A.; FERREIRA NETO, M.; HOLANDA, A. C. Qualidade da água para irrigação. IN: GHEYI, H. R.; DIAS, N. S.; LACERDA, C. F. Manejo da salinidade na agricultura: Estudos básicos e aplicados. Fortaleza: Instituto Nacional de Ciência e Tecnologia em Salinidade, 2010. p. 43-61.

IBGE. Levantamento Sistemático da Produção Agrícola - junho 2017. Disponível em: https://sidra.ibge.gov.br/home/lspa/brasil. Acesso em 17/07/2017.

JEFFERY, S.; VERHEIJEN, F. G. A.; VAN DER VELDE, M.; BASTOS, A. C. A quantitative review of the effects of biochar application to soils on crop productivity using meta-analysis. Agriculture, Ecosystems and Environment, v. 144, n. 1, p. 175187, 2011. 10.1016/j.agee.2011.08.015

LACERDA, C. F.; SOUSA, G. G.; SILVA, F. L. B.; GUIMARÃES, F. V. A.; SILVA, G. L.; CAVALCANTE, L. F. Soil salinization and maize and cowpea yield in the crop rotation system using saline waters. Engenharia Agrícola, v.31, n.4, p.663-675, 2011. 10.1590/S0100-69162011000400005

LEHMANN, J.; SILVA JR.; J. P., STEINER, C.; NEHLS, T.; ZECH, W.; GLASER, B. Nutrient availability and leaching in an archaeological Anthrosol and a Ferralsol of the Central Amazon basin: fertilizer, manure and charcoal amendments. Plant and Soil, v. 249, n. 2, p. 343-357. 2003. 10.1023/A:1022833116184

LEWIS, O. A. M.; LEIDI, E. O; LIPS, S. H. Effect of nitrogen source on growth response to salinity stress in maize and wheat. New Phytologist, v. 111, n. 2, p. 155-160, 1989. 10.1111/j.1469-8137.1989.tb00676.x

LIU, Z.; DUGAN, B.; MASIELLO, C. A.; GONNERMANN, H. M. Biochar particle size, shape, and porosity act together to influence soil water properties. PLoS ONE 12(6): e0179079. 2017. 10.1371/journal.pone.0179079

MACHADO, V. J.; SOUZA, C. H. E. Disponibilidade de fósforo em solos com diferentes texturas após aplicação de doses crescentes de fosfato monoamônico de liberação lenta. Bioscience Journal, v. 28, suplemento 1, p. 1-7, 2012.

MADARI, B. E.; COSTA, A. R.; CASTRO, L. M.; SANTOS, J. L. S.; BENITES, V. M.; ROCHA, A. O.; MACHADO, P. L. O. A. Carvão vegetal como condicionador de solo para arroz de terras altas (cultivar primavera): Um estudo prospectivo. Santo Antônio de Goiás: Embrapa Arroz e Feijão, 125. 2006. 2p. (Comunicado Técnico 125).

MAIA, C. M. B. F.; SOHI, S. P. The effect of biochar on soilcarbon stabilization in a highly SOM depleted soil. 3rd IBI Meeting, Rio de Janeiro, Proceedings, 2010. 
MALAVOLTA, E. Manual de nutrição mineral de plantas. São Paulo: Editora Agronômica Ceres, 2006. 638 p.

MELO, I. G. C. Efeitos do carvão vegetal no solo e sobre cultivos de feijão-caupi em ambiente protegido. 2016. 97f. Tese (Doutorado em Manejo de Solo e Água) Universidade Federal Rural do Semi-Árido, Mossoró. 2017.

MIRANDA, M. A.; OLIVEIRA, E. E. M.; SANTOS, K. C. F.; FREIRE, M. B. G. S.; ALMEIDA, B. G. Condicionadores químicos e orgânicos na recuperação de solo salino-sódico em casa de vegetação. Revista Brasileira de Engenharia Agrícola e Ambiental, v. 15, n. 5, p. 484-490, 2011. 10.1590/S141543662011000500008

MOREIRA, S. G.; LUPPI, R. M.; LIMA, C. G.; MARUCCI, R. C.; RESENDE, Á. V.; BORGES, I. D. Massa seca e macronutrientes acumulados em plantas de milho cultivadas sob diferentes espécies de cobertura. Revista Brasileira de Milho e Sorgo, v.13, n.2, p. 218-231, 2014. 10.18512/19806477/rbms.v13n2p218-231

NÓBREGA, I. P. C. Efeitos do biochar nas propriedades físicas e químicas do solo: sequestro de carbono no solo. 2011. $38 \mathrm{f}$. Dissertação (Mestrado em Engenharia do Ambiente) Universidade Técnica de Lisboa, Lisboa, 2011.

NOVAK, J. M.; RO, K. S.; OK, Y. S.; SIGUA, G. C.; SPOKAS, K. A.; UCHIMIYA, S. M.; BOLAN, N. Biochars multifunctional role as a novel technology in the agricultural, environmental, and industrial sectors. Chemosphere, v. 142, n. 1, p. 1-3, 2016. 10.1016/j.chemosphere.2015.06.066

PETTER, F. A. Biomassa carbonizada como condicionador de solo: aspectos agronômicos e ambientais do seu uso em solos de cerrado. 2010.130 f. Tese (Doutorado em Agronomia) Universidade Federal de Goiás, Goiânia. 2010.

PETTER, F. A.; MADARI, B. E. Biochar: Agronomic and environmental potential in Brazilian savannah soils. Revista Brasileira de Engenharia Agrícola e Ambiental, v. 16, n. 7, p. 761-768, 2012. 10.1590/S1415-43662012000700009

RAJKOVICH, S.; ENDERS, A.; HANLEY, K.; HYLAND, C.; ZIMMERMAN, A. R.; LEHMANN, J. Corn growth and nitrogen nutrition after additions of biochars with varying properties to a temperate soil. Biology and Fertility of Soils, v. 48 , n. $\underline{3}$, p. 271-284, 2012. 10.1007/s00374-011-0624-7

RICHARDS, L. A. Diagnosis and improvement of saline and alkali soils. Washington: U. S. Salinity Laboratory, 1954. (USDA. Agriculture handbook, 60).

SANTOS, H. G. dos; JACOMINE, P. K. T.; ANJOS, L. H. C.; OLIVEIRA, V. A.; LUMBRERAS, J. F.; COELHO, M. R.; ALMEIDA, J. A.; CUNHA, T. J. F.; OLIVEIRA, J. B. Sistema brasileiro de classificação de solos. 3.ed. Brasília: Embrapa, 2013.353p.
SHARPLEY, A. N.; MEISINGER, J. J.; POWER, J. F., SUAREZ, D. L. Root extraction of nutrients associated with long-term soil management. In: STEWART, B. (Ed.), Advances in soil science. New York: Springer Verlag, 1992. p.151-217.

SILVA, E. M.; LACERDA, F. H. D.; MEDEIROS, A. S.; SOUZA, L. P.; PEREIRA, F. H. F. Métodos de aplicação de diferentes concentrações de $\mathrm{H}_{2} \mathrm{O}_{2}$ em milho sob estresse salino. Revista Verde de Agroecologia e Desenvolvimento Sustentável, v. 11, n.3, p. 1-7, 2016. 10.18378/rvads.v11i3.4343

SOHI, S. P.; KRULL, E.; LOPEZ-CAPEL, E.; BOL, R. A review of biochar and its use and function in soil. Advances in Agronomy, v. 105 , p. $47-82,2010.10 .1016 /$ S00652113(10)05002-9

SOUSA, G. G.; LACERDA, C. F.; SILVA, G. L.; FREITAS, C. A. S.; CAVAlCANTE, L. F.; SOUSA, C. H. C. Acumulação de biomassa, teores e extração de micronutrientes em plantas de milho irrigadas com águas salinas. Revista Agropecuária Técnica, v. 31, n. 2, p. 1-10, 2010.

SOUSA, G. G.; MARINHO, A. B.; ALBUQUERQUE, A. H. P.; VIANA, T. V. A.; AZEVEDO, B. M. Crescimento inicial do milho sob diferentes concentrações de biofertilizante bovino irrigado com águas salinas. Revista Ciência Agronômica, v. 43, n. 2 , p. $237-245,2012$. 10.1590/S1806-66902012000200005

SOUZA, F. G.; FARIAS, S. A. R.; FERREIRA FILHO, J. G. A.; BRITO, K. Q. D. Comportamento dos teores de sais em perfil de solo com vegetação nativa e culturas irrigadas. Revista Verde de Agroecologia e Desenvolvimento Sustentável, v. 11, n. 2, p. 60-65, 2016. 10.18378/rvads.v11i2.4049

STEINER, C.; DAS, K. C.; MELEAR, N.; LAKLY, D. Reducing nitrogen loss during poultry litter composting using biochar. Journal of Environmental Quality, v. 39, n. 4, p. 12361242, 2010. 10.2134/jeq2009.0337

THOMAS, S. C.; FRYE, S.; GALE, N.; GARMON, M.; LAUNCHBURY, R.; MACHADO, N.; MELAMED, S.; MURRAY, J.; PETROFF, A.; WINSBOROUGH, C. Biochar mitigates negative effects of salt additions on two herbaceous plant species. Journal of Environmental Management, v. 129, n. 1, p. 62-68, 2013. 10.1016/j.jenvman.2013.05.057

UZOMA, K. C.; INOUE, M.; ANDRY, H.; FUJIMAKI, H.; ZAHOOR, A.; NISHIHARA, E. Effect of cow manure biochar on maize productivity under sandy soil condition. Soil Use and Management, v. 27, n. 2, p. 205-212, 2011. 10.1111/j.14752743.2011.00340.x

ZHANG, Y.; IDOWU, O. J.; BREWER, C. E. Using agricultural residue biochar to improve soil quality of desert soils. Agriculture, v. 6, n. 1, p.1-11, 2016. 10.3390/agriculture6010010 